\title{
JADARA
}

Volume 10

Number 5 PRWAD Monograph No. 4

Article 7

October 2019

\section{Organization of the Conference}

None None

None

Follow this and additional works at: https://repository.wcsu.edu/jadara

\section{Recommended Citation}

None, N. (2019). Organization of the Conference. JADARA, 10(5). Retrieved from

https://repository.wcsu.edu/jadara/vol10/iss5/7 


\section{ORGANIZATION OF THE CONFERENCE}

In accordance with the comments and recommendations of respondents to the psychological survey, plans were initiated by the project director for a follow-up national conference to focus on the training needs of psychological service providers to deaf individuals. One of the responding institutions, the South Carolina School for the Deaf and the Blind, enthusiastically offered to host such a conference.

Further discussion of the proposal was held at an informal meeting of representatives of the South Carolina School together with leaders in services for the deaf representing various east-coast facilities, and the project director of the psychological survey. The proposal for a national conference was unanimously endorsed.

The next step was to obtain funds to finance the conference. Application was made to the Social and Rehabilitation Service of the Department of Health, Education, and Welfare which had partially funded the survey. Text and budget of the application were developed from suggestions made at the above-mentioned meeting plus the work of a small committee consisting of Robert Millard, Assistant Superintendent of the South Carolina School, Ruth R. Green, Director, Counseling and Social Services as well as Assistant Administrative Director of the New York League for the Hard of Hearing, and Edna S. Levine, Director of the New York University program Explorations in the Psychology of Deafness and project director of the psychological survey.

In August 1974 supplemental funds were awarded Explorations in the Psychology of Deafness for the purpose of conducting a national conference on the preparation and training of psychologists to the deaf.

\section{Objectives of the Conference}

As stated in the grant application, the broad objective of the conference was to develop the guidelines necessary for the eventual establishment of programs of preparation and training for providers of psychological services to the deaf. Toward this end, the specific objectives were to: 
1. Review the functions qualified psychologists are normally expected to carry out in line with their professional training and responsibilities.

2 . Analyze and determine the functions expected of psychological service providers to the deaf in the principal settings in which they practice.

3. Analyze and determine the special bodies of knowledge, skills, and competencies needed in order to conduct these functions effectively with a deaf clientele.

4. Determine the courses of study and various types of training programs through which these competencies can be acquired.

5. Propose ideas concerning the issues of program accreditation and worker certification.

\section{Organizing Committees}

The task of organizing and operationalizing the conference was carried out by a number of committees. (See Appendix for listings of committee members.) The key committee was the Planning Committee. Since the conference was of national scope, regional location of its members was important for national representation. The members of this committee were therefore selected on the basis of qualification, regional location, and availability. Regions of heavy deaf population were accorded more than one representative, but every region was represented by at least one member of the Planning Committee.

The responsibilities of the Planning Committee were to: (1) select the dates and site for the conference; (2) propose guides for the selection of participants; (3) develop the program content and topics; (4) develop the plan of operation of the conference; (5) nominate group leaders and recorders and suggest interpreters; (6) submit the names of desired participants from their respective regions as well as from the field at large; (7) serve as decision-making body on key matters that might arise; and (8) empower the Executive Committee to act in its best judgment on other relevant matters.

The functions of the Executive Committee were to: (1) carry out the plan of operation proposed by the Planning Committee; (2) serve as communicative link through the distribution of reports and informational memos and materials among the committees and with the participants; (3) develop, distribute, and collate forms for obtaining professional background information from the participants; and (4) manage budgetary details.

The function of the Participant Selection Committee was, as the name implies, to be responsible for the selection of participants to the conference.

The functions of the Program Committee were to: (1) organize the proposals of the Planning Committee into program format; (2) itemize the program by date, time, and topic; (3) assemble informational packets for the conference participants; and (4) oversee organizational details at the conference.

The committees all worked in close collaboration with one another. 


\section{Selection and Backgrounds of Participants}

Professional Background forms previously distributed to conference candidates and collated by the Executive Committee indicated that a wide variety of personnel were performing psychological services for the deaf. Some few were qualified school, clinical, and counseling psychologists. Others were 'psychologists' by job title rather than qualification. Still others were audiologists, speech therapists, guidance counselors, social and welfare workers, teachers, denominational workers, etc. Among the non-psychologists were those whose experiences with the deaf made them better workers than were the qualified psychologists without experience. This state of affairs raised numbers of questions regarding participant selection.

It was the decision of the organizing committees that input from all types of providers of psychological services to the deaf would be of value, and that no barriers should be raised purely on the basis of academic qualification. The point was also made by the Planning Committee that problems of psychological practice with the deaf touch not only psychologists but also such involved personnel as administrators, employers, consumers, team colleagues from other disciplines; and that, for maximum input, it was important to include such persons as participants. In effect then the conference had multidisciplinary input from a variety of levels of experience and background.

To insure optimum work conditions, it was further agreed that the conference should number no more than about 80 participants. However, the pool of names from which the participants were to be selected numbered several hundred. These included: (1) names submitted by members of the Planning Committee; (2) respondents to the psychological survey; and (3) individuals who had written in requesting invitations, some of whom offered to fund their own expenses. To add to the problem, funding was available for only 66 participants including interpreters. The Selection Committee had their work cut out for them. They proceeded with a preliminary screening

1. Names from all sources were grouped according to category of setting in which the candidate practiced, and by home state.

2. In each home state, the names were next grouped by discipline, and by the specific facility in which the candidate worked.

3. A review was then made based on the candidate's professional level in terms of certification, position title, degree, or other form of professional recognition.

On completion of this preliminary screening, the Selection Committee proceeded along the following lines:

1. Names submitted by the Planning Committee members were reviewed, and those were reserved for later selection who had been recommended by 3 or more members. 


\section{ORGANIZATION OF THE CONFERENCE}

2. Names of survey-respondents and 'write-ins' were next reviewed, and those were reserved for later selection who had been recommended at the Planning Committee level and/or who possessed desirable qualifications and/or experiences.

3. From the remainder of the pool, a random selection was made based roughly on discipline.

4. Cross-checking was then conducted to aim for a fairly representative balance.

5. From the still excessive listing thus produced, exclusions were made based on the number of personnel representing the same facility, the same state, or the same discipline if an over-representation existed in that particular specialty.

The list of candidates finally obtained totaled 104. Thanks to the fact that a number had offered to pay their own way, it was possible to break this total down to 83 selected participants and 21 alternates representing every state in the continental United States plus a representative from Sweden. (See Appendix for listing of participants.)

The service settings represented by the participants included: special schools and classes for the deaf (33); rehabilitation agencies and centers (13); special services in hearing and speech and in mental health (8); college and university based programs on the deaf (11); national organizations and agencies of and for the deaf (6); parent organizations (3); denominational services (2). The disciplines represented included: psychology, education, rehabilitation, counseling, administration, denominational, audiology, speech, and hearing therapy, interpreting, and parentage. The highest degrees represented were the Ph.D. and Ed.D. (29) and master's level degrees (32).

Of the total number of multidisciplinary participants, forty-two were engaged in providing psychological services to the deaf. Included were academically qualified psychologists, and those not so qualified. Two psychologists were Fellows of the American Psychological Association; 14 were Members of APA; and 3 were Associates. The Fellows and Members represented the following Divisions of the APA: General Psychology, Educational Psychology, School Psychology, Rehabilitation Psychology, Experimental Psychology, Psychotherapy, Personality and Social Psychology, Clinical Psychology and State Affairs. Several were members of more than one Division.

Finally, 12 of the participants were hearing impaired, with 7 of the 12 designating they were 'deaf'.

\section{The Consumers}

Consumers of psychological services represented at the conference included:

1. Direct recipients of psychological services such as rehabilitation clients.

2. Facilities employing psychologists or psychological consultants, such as schools, rehabilitation centers, and other facilities serving a deaf clientele. 
3. Institutions and organizations utilizing psychological services on a referral basis.

4. Purchasers of psychological services not directly involved as consumer or recipient, such as government agencies supporting the cost of psychological services.

5. Indirect recipients of psychological services such as parents.

The interests of the deaf were further represented by local and national organizations of and for the deaf of which the major national ones represented at the Conference included: the Alexander Graham Bell Association for the Deaf and its affiliated parents' organization, the Conference of Executives of American Schools for the Deaf, the Convention of American Instructors of the Deaf, the National Association of the Deaf, and the Professional Rehabilitation Workers with the Adult Deaf together with its affiliated parents' organization.

\section{Topics for Discussion}

Topics relevant to the objectives of the Conference were solicited in advance from participants and committee members. These were reviewed and categorized. The overwhelming majority were classifiable under one or another of the specific objectives listed above. These then became the Conference topics.

It was hoped that other topics could be discussed informally during the course of the Conference if there were time. A few of the more provocative ones submitted by participants are quoted as follows:

1. After we define the issues for full-time workers, how can be extend this for part-time workers.

2. What about personnel who are not trained psychologists but who provide psychological services of various kinds.

3. What would be the manner of designating "certified/qualified" workers and which organization shall confer such recognition.

4. What would be the manner of identifying "certified/qualified" psychologists to other professionals, service organizations, and the public.

5 . What about training paraprofessional aides.

6. On the organization-chart of a facility serving a deaf clientele, what should the staff position-designation be of a qualified, full-time psychologist.

\section{Distribution of Orientative Materials}

Realizing that some participants including group leaders and consumers were less well informed than others about the duties qualified psychologists are trained to carry out, the Executive Committee undertook to distribute a variety of relevant orientative materials to participants and group leaders.

Some of the material was summarized from a number of authoritative sources by various committee members. Where this was not possible and where the original documents could not be distributed, references were provided. 
Materials distributed in advance of the conference included: (1) the functions of school, clinical, and counseling psychologists; (2) the qualifications of clinical and counseling psychologists as designated by the United States Civil Service Commission; (3) accreditation criteria and procedures of the American Psychological Association; and (4) references to various publications dealing with school psychology and to journal articles dealing with certification issues, problems, and proposals. A follow-up distribution was made to members of the Planning Committee of the article Standards for Providers of Psychological Services by the APA Task Force on standards for service facilities on its appearance in the American Psychologist in June 1975.

Material relating to psychological practice with the deaf was also distributed to conference participants. This consisted of a report of the psychological survey of tests and practices with the deaf, noted previously, (Levine, 1974), and a preprint of a chapter for a then forthcoming book, on the psychological evaluation of deaf rehabilitation clients (Levine, 1976).

In addition, participants were kept closely informed of proceedings at committee meetings through continuing reports and memos. Also distributed was an illustrative 'flow-chart' of functions $\rightarrow$ related competencies $\rightarrow$ related training needs, devised by the project director for the particular guidance of group leaders. Finally, group leaders were provided in advance of the conference with the names and professional background summaries of the participants assigned to their respective work groups.

\section{Operational Procedures at the Conference}

The Conference was held at the Ramada Inn, Spartanburg, South Carolina, from February 23rd through February 26th, 1975 with the South Carolina School for the Deaf and the Blind acting as host facility under the leadership of its Superintendent, Newton F. Walker, and the able administration of its Assistant Superintendent, Robert Millard.

The plan of procedure was through work groups numbering 5 in all. Four of the groups each represented a particular setting serving deaf persons: (1) rehabilitation; (2) school; (3) mental health; and (4) hearing and speech. Members of the groups included psychologists as well as non-psychologist service providers and consumers of psychological services. A fifth work group was composed mainly of psychologists and concerned itself chiefly with the overall role of psychologists to the deaf and various related issues.

Each group had its own group leader, recorder, and interpreters. Group leaders and recorders met with the Project Director and the Program Chairperson a day before the conference for guides, questions, discussion, and orientation. At the same time, a meeting was held for interpreters for the same purposes under the able leadership of a Coordinating Interpreter, Mary Anne Royster. Additional breakfast meetings were held during the course of the conference. 
In order to guard against time-consuming discussion on less timely topics and issues, each group leader was provided with a check-list of 'high priority' topics that demanded first attention. In review, these included: (1) a survey of functions ordinarily rendered by psychological service providers working with non-deaf clients; (2) functions actually rendered by psychological service providers to the deaf; (3) functions that should be rendered by such personnel; (4) the competencies required of psychological service providers to the deaf in order to function effectively; (5) types of training strategies whereby these competencies could be acquired; and (6) issues of certification and accreditation. Each group was scheduled to cover the same topics at the same time, and participants remained with the same work group throughout the conference. A summary of the proceedings of the respective groups was given by its recorder in plenary session at the close of each work day.

The opening session of the conference took place the evening preceding the first work day. The program included an official welcome by Superintendent Newton F. Walker; a Keynote Address by James F. Garrett, Executive Director of Research of the Rehabilitation Service Administration, Department of Health, Education, and Welfare; a summary of the conference background by Project Director Edna S. Levine; and a review of workshop format and procedures by Ruth R. Green, Program Chairperson, and Robert Millard, Administrative Supervisor.

The session closed with a performance by pupils and staff members of the South Carolina School called "A Look at Ourselves", consisting of a number of serio-comic skits on psychological sessions with the deaf clients. The skits were written and directed by Robert Bremer, Chaplain of the South Carolina School, and Charles McKinney, Rehabilitation Counselor at the school. The performance served as an excellent ice-breaker for the heavy work sessions of the next few days.

It was the hope of the Project Director that in the course of these work sessions it would come to be realized that the practice of psychology with deaf individuals is a distinct professional specialty which, like all other professional specialties, cannot be achieved without special preparation and training. 